\title{
An inertial S-iteration process
}

\section{Aniruth Phon-on ${ }^{*}$ D, Nifatamah Makaje', Areeyuth Sama-Ae ${ }^{1}$ and Kittiya Khongraphan}

"Correspondence:

aniruth.p@psu.ac.th

${ }^{1}$ Department of Mathematics and Computer Science, Faculty of

Science and Technology, Prince of

Songkla University, Pattani, Thailand

\begin{abstract}
In this paper, we establish a new iteration method, called an InerSP (an inertial S-iteration process), by combining a modified S-iteration process with the inertial extrapolation. This strategy is for speeding up the convergence of the algorithm. We then prove the convergence theorems of a sequence generated by our new method for finding a common fixed point of nonexpansive mappings in a Banach space. We also present numerical examples to illustrate that the acceleration of our algorithm is effective.
\end{abstract}

MSC: $47 \mathrm{H} 04 ; 54 \mathrm{H} 25$

Keywords: Common fixed point; MIS-iteration; Nonexpansive mapping; Inertial extrapolation

\section{Introduction}

In the last half century, mathematicians have been studied the approximation methods for fixed point problems and various iteration schemes for several classes of nonexpansive mappings to solve some mathematical problems such as convex optimization problems, convex feasibility problems, and variational inequalities problems. The details of those studies can be found in [1-12].

In 2008, Mainge [13] studied convergence of the inertial Mann algorithm by combining the Mann algorithm and the inertial extrapolation:

$$
\begin{aligned}
& w_{n}=x_{n}+\alpha_{n}\left(x_{n}-x_{n-1}\right), \\
& x_{n+1}=w_{n}+\beta_{n}\left[S\left(w_{n}\right)-w_{n}\right],
\end{aligned}
$$

for each $n \geq 1$. The study is for speeding up the convergence of the given algorithm. The author showed that the sequence $\left\{x_{n}\right\}$ converges weakly to a fixed point of the mapping $S$ under certain assumptions. The author also applied the method to convex feasibility problems, fixed point problems and monotone inclusions.

Dong et al. [14] introduced a modified inertial Mann algorithm and an inertial CQalgorithm by unifying the accelerated Mann algorithm with the inertial extrapolation as follows: Let $T: \mathcal{H} \rightarrow \mathcal{H}$ be a nonexpansive mapping such that $\operatorname{Fix}(T) \neq \emptyset$. Choose $\mu \in$ $(0,1), \lambda>0$ and $x_{0}, x_{1} \in \mathcal{H}$ arbitrarily and set $d_{0}:=\left(T\left(x_{0}\right)-x_{0}\right) / \lambda$. Compute $d_{n+1}$ and $x_{n+1}$

(c) The Author(s) 2019. This article is distributed under the terms of the Creative Commons Attribution 4.0 International License (http://creativecommons.org/licenses/by/4.0/), which permits unrestricted use, distribution, and reproduction in any medium, provided you give appropriate credit to the original author(s) and the source, provide a link to the Creative Commons license, and indicate if changes were made. 
as follows:

$$
\begin{aligned}
& w_{n}=x_{n}+\alpha_{n}\left(x_{n}-x_{n-1}\right), \\
& d_{n+1}=\frac{1}{\lambda}\left(T\left(w_{n}\right)-w_{n}\right)+\beta_{n} d_{n}, \\
& y_{n}=w_{n}+\lambda d_{n+1}, \\
& x_{n+1}=\mu \gamma_{n} w_{n}+\left(1-\mu \gamma_{n}\right) y_{n},
\end{aligned}
$$

for each $n \geq 1$. Under some conditions they proved that the sequence $\left\{x_{n}\right\}$ generated by this algorithm converges weakly to a fixed point of $T$. They also studied an inertial CQalgorithm by combining the CQ-algorithm and the inertial extrapolation defined as follows: Let $\mathcal{H}$ be a Hilbert space and $T: \mathcal{H} \rightarrow \mathcal{H}$ be a nonexpansive mapping such that $\operatorname{Fix}(T) \neq \emptyset$. Let $\left\{\alpha_{n}\right\}_{n=0}^{\infty} \subset\left[\alpha_{1}, \alpha_{2}\right], \alpha_{1} \in(-\infty, 0], \alpha_{2} \in[0, \infty),\left\{\beta_{n}\right\}_{n=0}^{\infty} \subset\left[\beta_{1}, 1\right], \beta_{1} \in(0,1)$. Set $x_{0}, x_{1} \in \mathcal{H}$ arbitrarily. Define the iterative sequence $\left\{x_{n}\right\}$ by the following iteration process:

$$
\begin{aligned}
& w_{n}=x_{n}+\alpha_{n}\left(x_{n}-x_{n-1}\right), \\
& y_{n}=\left(1-\beta_{n}\right) w_{n}+\beta_{n} T w_{n}, \\
& C_{n}=\left\{z \in \mathcal{H}:\left\|y_{n}-z\right\| \leq\left\|w_{n}-z\right\|\right\}, \\
& Q_{n}=\left\{z \in \mathcal{H}:\left\langle x_{n}-z, x_{n}-x_{0}\right\rangle \leq 0\right\}, \\
& x_{n+1}=P_{C_{n} \cap Q_{n}} x_{0} .
\end{aligned}
$$

They showed that the sequence $\left\{x_{n}\right\}$ converges in norm to $P_{\mathrm{Fix}(T)}\left(x_{0}\right)$. In this study, they also performed numerical experiments to illustrate that the modified inertial Mann algorithm and inertial CQ-algorithm significantly reduced the running time compared with some previous methods without the inertial extrapolation. Some studies of the inertial algorithm can be found in [15-23].

Suparatulatorn et al. [24] introduced a modified S-iteration process defined as follows: $x_{0} \in C$ and

$$
\begin{aligned}
& y_{n}=\left(1-\beta_{n}\right) x_{n}+\beta_{n} S_{1} x_{n}, \\
& x_{n+1}=\left(1-\alpha_{n}\right) S_{1}\left(x_{n}\right)+\alpha_{n} S_{2}\left(y_{n}\right),
\end{aligned}
$$

$n \geq 0$, where $C$ is a nonempty subset of a real Banach space, two sequences $\left\{\alpha_{n}\right\}$ and $\left\{\beta_{n}\right\}$ are in the interval $(0,1)$ and $S_{1}, S_{2}: C \rightarrow C$ are G-nonexpansive mappings. Under some given conditions, they proved weak and strong convergence theorems of this iteration process for finding common fixed points of two G-nonexpansive mappings in a uniformly convex Banach space. They also provided an example from a numerical experiment which supported the idea that the sequence generated by the modified S-iteration converges faster than the one generated by an Ishikawa iteration. So, to obtain a faster algorithm revised from a modified S-iteration process, it should be combined with the inertial extrapolation as well.

Therefore, in this article, we focus on a combination of modified S-iteration process and the inertial extrapolation to obtain a new method which accelerates the approximation of 
a fixed point of a nonexpansive mapping in a Banach space defined as follows: Let $\mathcal{H}$ be a Banach space and $S_{1}, S_{2}: \mathcal{H} \rightarrow \mathcal{H}$ be nonexpansive mappings such that $F=\operatorname{Fix}\left(S_{1}\right) \cap$ $\operatorname{Fix}\left(S_{2}\right) \neq \emptyset$. Define

$$
\begin{aligned}
& \omega_{n}=x_{n}+\gamma_{n}\left(x_{n}-x_{n-1}\right), \\
& y_{n}=\left(1-\beta_{n}\right) \omega_{n}+\beta_{n} S_{1}\left(\omega_{n}\right), \\
& x_{n+1}=\left(1-\alpha_{n}\right) S_{1}\left(\omega_{n}\right)+\alpha_{n} S_{2}\left(y_{n}\right),
\end{aligned}
$$

$n \geq 1$, where $\left\{\gamma_{n}\right\},\left\{\alpha_{n}\right\}$ and $\left\{\beta_{n}\right\}$ satisfy:

(D1) $\sum_{n=1}^{\infty} \gamma_{n}<\infty,\left\{\gamma_{n}\right\} \subset[0, \gamma], 0 \leq \gamma<1,\left\{\alpha_{n}\right\},\left\{\beta_{n}\right\} \subset[\delta, 1-\delta]$ for some $\delta \in(0,0.5)$;

(D2) $\left\{S_{i}\left(\omega_{n}\right)-\omega_{n}\right\}$ is bounded for $i=1,2$;

(D3) $\left\{S_{i}\left(\omega_{n}\right)-y\right\}$ is bounded for any $y \in F$ for $i=1,2$.

We prove, under some assumptions, the weak and strong convergence of our new iteration process for finding common fixed points of $S_{1}$ and $S_{2}$.

\section{Preliminaries}

In this section we review some definitions and lemmas which will be used in the next section. We start with the following identity that will be used several times in the paper:

$$
\|\alpha x+(1-\alpha) y\|^{2}=\alpha\|x\|^{2}+(1-\alpha)\|y\|^{2}-\alpha(1-\alpha)\|x-y\|^{2},
$$

for all $\alpha \in \mathbb{R}, x, y \in \mathcal{H}$.

Definition 2.1 A Banach space $X$ is said to have Opial's property if whenever a sequence $\left\{x_{n}\right\}$ in $X$ converges weakly to $x$, then

$$
\liminf _{n \rightarrow \infty}\left\|x_{n}-x\right\| \leq \liminf _{n \rightarrow \infty}\left\|x_{n}-y\right\|
$$

for all $y \in X, y \neq x$.

Definition 2.2 ([25]) Let $C$ be a nonempty closed convex subset of a real uniformly convex Banach space $X$. The mappings $S_{1}$ and $S_{2}$ on $C$ are said to satisfy Condition $B$ if there exists a nondecreasing function $f:[0, \infty) \rightarrow[0, \infty)$ with $f(0)=0$ and $f(r)>0$ for $r>0$ such that, for all $x \in C$,

$$
\max \left\{\left\|x-S_{1}(x)\right\|,\left\|x-S_{2}(x)\right\|\right\} \geq f(d(x, F))
$$

where we denote $F=\operatorname{Fix}\left(S_{1}\right) \cap \operatorname{Fix}\left(S_{2}\right)$ and $\operatorname{Fix}\left(S_{i}\right)$ is the set of fixed points of $S_{i}$ for all $i=1,2$.

Definition 2.3 ([25]) Let $C$ be a subset of a metric space (X,d). A mapping $S: C \rightarrow C$ is semicompact if for a sequence $\left\{x_{n}\right\}$ in $C$ with $\lim _{n \rightarrow \infty} d\left(x_{n}, S\left(x_{n}\right)\right)=0$, there exists a subsequence $\left\{x_{n_{i}}\right\}$ of $\left\{x_{n}\right\}$ such that $x_{n_{i}} \rightarrow p \in C$.

Lemma 2.4 ([26]) Let $X$ be a uniformly convex Banach space, and $\alpha_{n}$ be a sequence in $[\delta, 1-\delta]$ for $\delta \in(0,1)$. Suppose that sequences $\left\{x_{n}\right\}$ and $\left\{y_{n}\right\}$ in $X$ are such that 
$\liminf _{n \rightarrow \infty}\left\|x_{n}\right\| \leq c, \liminf _{n \rightarrow \infty}\left\|y_{n}\right\| \leq c$ and $\liminf _{n \rightarrow \infty}\left\|\alpha_{n} x_{n}+\left(1-\alpha_{n}\right) y_{n}\right\|=c$ for some $c \geq 0$. Then $\liminf _{n \rightarrow \infty}\left\|x_{n}-y_{n}\right\|=0$.

In 2002, Berinde [27] compared the rate of convergence between the two iterative methods by using the following definition.

Definition 2.5 Let $\left\{a_{n}\right\}$ and $\left\{b_{n}\right\}$ be two sequences of positive numbers that converges to $a$ and $b$, respectively. Assume there exists

$$
\lim _{n \rightarrow \infty} \frac{\left|a_{n}-a\right|}{\left|b_{n}-b\right|}=l
$$

i. If $l=0$, then it is said that the sequence $\left\{a_{n}\right\}$ converges to $a$ faster than the sequence $\left\{b_{n}\right\}$ to $b$.

ii. If $0<l<\infty$, then we say that the sequence $\left\{a_{n}\right\}$ and $\left\{b_{n}\right\}$ have the same rate of convergence.

Lemma 2.6 ([28]) Let $X$ be a Banach space that has Opial's property, and let $\left\{x_{n}\right\}$ be a sequence in $X$. Let $x, y$ in $X$ be such that $\lim _{n \rightarrow \infty}\left\|x_{n}-x\right\|$ and $\lim _{n \rightarrow \infty}\left\|x_{n}-y\right\|$ exist. If $\left\{x_{n_{j}}\right\}$ and $\left\{x_{n_{k}}\right\}$ are subsequences of $\left\{x_{n}\right\}$ that converge to $x$ and $y$, respectively, then $x=y$.

Lemma 2.7 ([29]) Let $\left\{\psi_{n}\right\},\left\{\delta_{n}\right\}$, and $\left\{\alpha_{n}\right\}$ be sequences in $[0, \infty)$ such that $\psi_{n+1} \leq \psi_{n}+$ $\alpha_{n}\left(\psi_{n}-\psi_{n-1}\right)+\delta_{n}$ for all $n \geq 1, \sum_{n=1}^{\infty} \delta_{n}<\infty$ and there exists a real number $\alpha$ with $0 \leq$ $\alpha_{n} \leq \alpha<1$ for all $n \geq 1$. Then the following hold:

1. $\sum_{n \geq 1}\left[\psi_{n}-\psi_{n-1}\right]_{+}<\infty$ where $[t]_{+}=\max \{t, 0\}$.

2. there exists $\psi^{*} \in[0, \infty)$ such that $\lim _{n \rightarrow \infty} \psi_{n}=\psi^{*}$.

Lemma 2.8 ([30]) Let $C$ be a nonempty set of a real Hilbert space $\mathcal{H}$ and $\left\{x_{n}\right\}$ a sequence in $\mathcal{H}$ such that the following two conditions hold:

1. for any $x \in C, \lim _{n \rightarrow \infty}\left\|x_{n}-x\right\|$ exists;

2. every sequential weak cluster point of $\left\{x_{n}\right\}$ is in $C$.

Then $\left\{x_{n}\right\}$ converges weakly to a point in $C$.

Lemma 2.9 ([30]) Let $C$ be a nonempty closed convex subset of a real Hilbert space $\mathcal{H}$, $T: C \rightarrow \mathcal{H}$ a nonexpansive mapping. Let $\left\{x_{n}\right\}$ be a sequence in $C$ and $x \in \mathcal{H}$ such that $x_{n} \rightarrow x$ and $T x_{n}-x_{n} \rightarrow 0$ as $n \rightarrow \infty$. Then $x \in \operatorname{Fix}(T)$.

\section{Results and discussions}

In this section we prove the weak and strong convergence of a sequence generated by the proposed algorithm for finding a common fixed point of two nonexpansive mappings.

Theorem 3.1 Let $X$ be a uniformly convex Banach space. Let $y \in F=\operatorname{Fix}\left(S_{1}\right) \cap \operatorname{Fix}\left(S_{2}\right)$. Let $\left\{x_{n}\right\}$ be a sequence defined by Eq. (5). If (D1), (D2) and (D3) hold, then

1. $\lim _{n \rightarrow \infty}\left\|x_{n}-y\right\|$ exists.

2. $\lim _{n \rightarrow \infty}\left\|x_{n}-S_{1}\left(x_{n}\right)\right\|=0=\lim _{n \rightarrow \infty}\left\|x_{n}-S_{2}\left(x_{n}\right)\right\|$. 
Proof

1. By the triangle inequality and the nonexpansiveness of $S_{1}$, we have

$$
\begin{aligned}
\left\|y_{n}-y\right\| & =\left\|\left(1-\beta_{n}\right) \omega_{n}+\beta_{n} S_{1}\left(\omega_{n}\right)-y\right\| \\
& \leq\left(1-\beta_{n}\right)\left\|\omega_{n}-y\right\|+\beta_{n}\left\|\left(S_{1}\left(\omega_{n}\right)-y\right)\right\| \\
& \leq\left(1-\beta_{n}\right)\left\|\omega_{n}-y\right\|+\beta_{n}\left\|\omega_{n}-y\right\| \\
& =\left\|\omega_{n}-y\right\| .
\end{aligned}
$$

So

$$
\begin{aligned}
\left\|x_{n+1}-y\right\| & =\left\|\left(1-\alpha_{n}\right) S_{1}\left(\omega_{n}\right)+\alpha_{n} S_{2}\left(y_{n}\right)-y\right\| \\
& =\left\|\left(1-\alpha_{n}\right)\left(S_{1}\left(\omega_{n}\right)-y\right)+\alpha_{n}\left(S_{2}\left(y_{n}\right)-y\right)\right\| \\
& \leq\left(1-\alpha_{n}\right)\left\|\left(S_{1}\left(\omega_{n}\right)-y\right)\right\|+\alpha_{n}\left\|\left(S_{2}\left(y_{n}\right)-y\right)\right\| .
\end{aligned}
$$

Using the nonexpansiveness of $S_{1}, S_{2}$ and (7), we have

$$
\begin{aligned}
\left\|x_{n+1}-y\right\| & \leq\left(1-\alpha_{n}\right)\left\|\left(S_{1}\left(\omega_{n}\right)-y\right)\right\|+\alpha_{n}\left\|\left(S_{2}\left(y_{n}\right)-y\right)\right\| \\
& \leq\left(1-\alpha_{n}\right)\left\|\omega_{n}-y\right\|+\alpha_{n}\left\|y_{n}-y\right\| \\
& \leq\left(1-\alpha_{n}\right)\left\|\omega_{n}-y\right\|+\alpha_{n}\left\|\omega_{n}-y\right\| \\
& =\left\|\omega_{n}-y\right\| .
\end{aligned}
$$

It is not difficult to see that $\left\{\omega_{n}-y\right\}$ is bounded. Indeed, by the conditions (D2) and (D3) and the triangle inequality,

$$
\begin{aligned}
\left\|\omega_{n}-y\right\| & =\left\|\omega_{n}-S_{1}\left(\omega_{n}\right)+S_{1}\left(\omega_{n}\right)-y\right\| \\
& \leq\left\|S_{1}\left(\omega_{n}\right)-\omega_{n}\right\|+\left\|S_{1}\left(\omega_{n}\right)-y\right\| \\
& \leq K,
\end{aligned}
$$

for some $K \in[0, \infty)$. That is, $\left\{\omega_{n}-y\right\}$ is bounded. Hence by (9), $\left\{x_{n}-y\right\}$ and $\left\{x_{n}-x_{n-1}\right\}$ are bounded. By the identity in (6),

$$
\begin{aligned}
\left\|\omega_{n}-y\right\|^{2} & =\left\|\left(1+\gamma_{n}\right)\left(x_{n}-y\right)-\gamma_{n}\left(x_{n-1}-y\right)\right\|^{2} \\
& =\left(1+\gamma_{n}\right)\left\|x_{n}-y\right\|^{2}-\gamma_{n}\left\|x_{n-1}-y\right\|^{2}+\gamma_{n}\left(1+\gamma_{n}\right)\left\|x_{n}-x_{n-1}\right\|^{2} .
\end{aligned}
$$

This implies that

$$
\begin{aligned}
\left\|x_{n+1}-y\right\|^{2} & \leq\left\|\omega_{n}-y\right\|^{2} \\
& =\left(1+\gamma_{n}\right)\left\|x_{n}-y\right\|^{2}-\gamma_{n}\left\|x_{n-1}-y\right\|^{2}+\gamma_{n}\left(1+\gamma_{n}\right)\left\|x_{n}-x_{n-1}\right\|^{2} .
\end{aligned}
$$

Denote $\Psi_{n}:=\left\|x_{n}-y\right\|^{2}$. Then (12) becomes

$$
\Psi_{n+1} \leq \Psi_{n}+\gamma_{n}\left(\Psi_{n}-\Psi_{n-1}\right)+\delta_{n}
$$


where $\delta_{n}=\gamma_{n}\left(1+\gamma_{n}\right)\left\|x_{n}-x_{n-1}\right\|^{2}$. Observe that by (D1),

$$
\begin{aligned}
\sum_{n=1}^{\infty} \delta_{n} & =\sum_{n=1}^{\infty} \gamma_{n}\left(1+\gamma_{n}\right)\left\|x_{n}-x_{n-1}\right\|^{2} \\
& \leq \sum_{n=1}^{\infty} \gamma_{n}(1+\gamma)(2 K)^{2} \\
& <\infty
\end{aligned}
$$

By Lemma 2.7(2), there exists $\Psi^{*} \in[0, \infty)$ such that $\lim _{n \rightarrow \infty} \Psi_{n}=\Psi^{*}$. This means that $\lim _{n \rightarrow \infty}\left\|x_{n}-y\right\|^{2}$ exists and, therefore, $\lim _{n \rightarrow \infty}\left\|x_{n}-y\right\|$ exists. This completes the proof of 1 .

2. Set $c=\lim _{n \rightarrow \infty}\left\|x_{n}-y\right\|$. By the nonexpansiveness of $S_{1}$ and $S_{2}$, we get

$$
\begin{aligned}
\left\|x_{n}-S_{i}\left(x_{n}\right)\right\| & \leq\left\|x_{n}-y\right\|+\left\|S_{i}\left(x_{n}\right)-y\right\| \\
& \leq\left\|x_{n}-y\right\|+\left\|x_{n}-y\right\| \\
& =2\left\|x_{n}-y\right\| .
\end{aligned}
$$

So, if $c=0$, then $\left\|x_{n}-S_{i}\left(x_{n}\right)\right\| \rightarrow 0$. Now assume that $c>0$. Note that $\sum_{n=1}^{\infty} \gamma_{n}<\infty$ implies $\lim _{n \rightarrow \infty} \gamma_{n}=0$. It follows from (11)

$$
\begin{aligned}
\lim _{n \rightarrow \infty}\left\|\omega_{n}-y\right\|^{2}= & \lim _{n \rightarrow \infty}\left(\left(1+\gamma_{n}\right)\left\|x_{n}-y\right\|^{2}-\gamma_{n}\left\|x_{n-1}-y\right\|^{2}\right. \\
& \left.+\gamma_{n}\left(1+\gamma_{n}\right)\left\|x_{n}-x_{n-1}\right\|^{2}\right) \\
= & \lim _{n \rightarrow \infty}\left\|x_{n}-y\right\|^{2} \\
= & c^{2} .
\end{aligned}
$$

That is, $\lim _{n \rightarrow \infty}\left\|\omega_{n}-y\right\|=c$. So, this forces

$\lim \sup _{n \rightarrow \infty}\left\|y_{n}-y\right\| \leq \lim \sup _{n \rightarrow \infty}\left\|\omega_{n}-y\right\|=c$. Next we will claim that $\liminf _{n \rightarrow \infty}\left\|y_{n}-y\right\| \geq c$. Since $S_{1}$ and $S_{2}$ are nonexpansive, by (6) we have

$$
\begin{aligned}
\left\|x_{n+1}-y\right\|^{2}= & \left(1-\alpha_{n}\right)\left\|\left(S_{1}\left(\omega_{n}\right)-y\right)\right\|^{2}+\alpha_{n}\left\|\left(S_{2}\left(y_{n}\right)-y\right)\right\|^{2} \\
& -\alpha_{n}\left(1-\alpha_{n}\right)\left\|S_{1}\left(\omega_{n}\right)-S_{2}\left(y_{n}\right)\right\|^{2} \\
\leq & \left(1-\alpha_{n}\right)\left\|\omega_{n}-y\right\|^{2}+\alpha_{n}\left\|y_{n}-y\right\|^{2} .
\end{aligned}
$$

Rearranging (17) and by (D1), we have

$$
\begin{aligned}
\left\|\omega_{n}-y\right\|^{2} & \leq\left\|y_{n}-y\right\|^{2}+\frac{1}{\alpha_{n}}\left(\left\|\omega_{n}-y\right\|^{2}-\left\|x_{n+1}-y\right\|^{2}\right) \\
& \leq\left\|y_{n}-y\right\|^{2}+\frac{1}{\delta}\left(\left\|\omega_{n}-y\right\|^{2}-\left\|x_{n+1}-y\right\|^{2}\right) .
\end{aligned}
$$

By (18) and (9), it yields $\liminf _{n \rightarrow \infty}\left\|y_{n}-y\right\|^{2} \geq c^{2}$ and so $\liminf _{n \rightarrow \infty}\left\|y_{n}-y\right\| \geq c$.

Since

$$
c \leq \liminf _{n \rightarrow \infty}\left\|y_{n}-y\right\| \leq \limsup _{n \rightarrow \infty}\left\|y_{n}-y\right\| \leq c,
$$


it follows that $\lim _{n \rightarrow \infty}\left\|y_{n}-y\right\|=c$.

Since

$$
\begin{aligned}
& \limsup _{n \rightarrow \infty}\left\|S_{1}\left(\omega_{n}\right)-y\right\| \leq \limsup _{n \rightarrow \infty}\left\|\omega_{n}-y\right\| \leq c, \\
& \limsup _{n \rightarrow \infty}\left\|S_{2}\left(y_{n}\right)-y\right\| \leq \limsup _{n \rightarrow \infty}\left\|y_{n}-y\right\| \leq c, \\
& \lim _{n \rightarrow \infty}\left\|\left(1-\beta_{n}\right)\left(\omega_{n}-y\right)+\beta_{n}\left(S_{1}\left(\omega_{n}\right)-y\right)\right\|=\lim _{n \rightarrow \infty}\left\|y_{n}-y\right\|=c,
\end{aligned}
$$

and

$$
\lim _{n \rightarrow \infty}\left\|\left(1-\alpha_{n}\right)\left(S_{1}\left(\omega_{n}\right)-y\right)+\alpha_{n}\left(S_{2}\left(y_{n}\right)-y\right)\right\|=\lim _{n \rightarrow \infty}\left\|x_{n+1}-y\right\|=c,
$$

by Lemma 2.4,

$$
\lim _{n \rightarrow \infty}\left\|S_{1}\left(\omega_{n}\right)-\omega_{n}\right\|=0
$$

and

$$
\lim _{n \rightarrow \infty}\left\|S_{1}\left(\omega_{n}\right)-S_{2}\left(y_{n}\right)\right\|=0
$$

However, we know that $y_{n}-\omega_{n}=\beta_{n}\left(S_{1}\left(\omega_{n}\right)-\omega_{n}\right)$ and $\omega_{n}-x_{n}=\gamma_{n}\left(x_{n}-x_{n-1}\right)$ which yield

$$
\begin{aligned}
0 & \leq \lim _{n \rightarrow \infty}\left\|y_{n}-\omega_{n}\right\| \\
& =\lim _{n \rightarrow \infty} \beta_{n}\left\|S_{1}\left(\omega_{n}\right)-\omega_{n}\right\| \\
& \leq \lim _{n \rightarrow \infty}\left\|S_{1}\left(\omega_{n}\right)-\omega_{n}\right\| \\
& =0
\end{aligned}
$$

and

$$
\begin{aligned}
\lim _{n \rightarrow \infty}\left\|\omega_{n}-x_{n}\right\| & =\lim _{n \rightarrow \infty} \gamma_{n}\left\|x_{n}-x_{n-1}\right\| \\
& =0
\end{aligned}
$$

Note that by (D2) and $\gamma_{n} \rightarrow 0$ we have

$$
\begin{aligned}
\lim _{n \rightarrow \infty}\left\|S_{1}\left(\omega_{n}\right)-x_{n}\right\| & \leq \lim _{n \rightarrow \infty}\left\|S_{1}\left(\omega_{n}\right)-\omega_{n}\right\|+\lim _{n \rightarrow \infty} \gamma_{n}\left\|x_{n}-x_{n-1}\right\| \\
& =0
\end{aligned}
$$

It follows that, by (20), (21), (22), (23) and the nonexpansiveness of $S_{1}$ and $S_{2}$, we have

$$
\begin{aligned}
0 & \leq \lim _{n \rightarrow \infty}\left\|S_{1}\left(x_{n}\right)-x_{n}\right\| \\
& \leq \lim _{n \rightarrow \infty}\left\|S_{1}\left(x_{n}\right)-S_{1}\left(\omega_{n}\right)\right\|+\lim _{n \rightarrow \infty}\left\|S_{1}\left(\omega_{n}\right)-x_{n}\right\|
\end{aligned}
$$




$$
\begin{aligned}
& \leq \lim _{n \rightarrow \infty}\left\|x_{n}-\omega_{n}\right\|+\lim _{n \rightarrow \infty}\left\|S_{1}\left(\omega_{n}\right)-x_{n}\right\| \\
& =0
\end{aligned}
$$

and

$$
\begin{aligned}
0 & \leq \lim _{n \rightarrow \infty}\left\|S_{2}\left(x_{n}\right)-x_{n}\right\| \\
& \leq \lim _{n \rightarrow \infty}\left\|S_{2}\left(x_{n}\right)-S_{2}\left(y_{n}\right)\right\|+\lim _{n \rightarrow \infty}\left\|S_{2}\left(y_{n}\right)-S_{1}\left(\omega_{n}\right)\right\|+\lim _{n \rightarrow \infty}\left\|S_{1}\left(\omega_{n}\right)-x_{n}\right\| \\
& \leq \lim _{n \rightarrow \infty}\left\|x_{n}-y_{n}\right\|+\lim _{n \rightarrow \infty}\left\|S_{2}\left(y_{n}\right)-S_{1}\left(\omega_{n}\right)\right\|+\lim _{n \rightarrow \infty}\left\|S_{1}\left(\omega_{n}\right)-x_{n}\right\| \\
& \leq \lim _{n \rightarrow \infty}\left\|x_{n}-\omega_{n}\right\|+\lim _{n \rightarrow \infty}\left\|\omega_{n}-y_{n}\right\| \\
& =0 .
\end{aligned}
$$

Therefore, $\lim _{n \rightarrow \infty}\left\|S_{1}\left(x_{n}\right)-x_{n}\right\|=0=\lim _{n \rightarrow \infty}\left\|S_{2}\left(x_{n}\right)-x_{n}\right\|$ as desired.

Theorem 3.2 Let $\mathcal{H}$ be a Banach space having Opial's property. Suppose that $S_{1}, S_{2}: \mathcal{H} \rightarrow$ $\mathcal{H}$ are two nonexpansive mappings with $F=\operatorname{Fix}\left(S_{1}\right) \cap \operatorname{Fix}\left(S_{2}\right) \neq \emptyset$. Then the sequence $\left\{x_{n}\right\}$ in (5) converges weakly to a common fixed point of $S_{1}$ and $S_{2}$.

Proof Let $y \in F$. By Theorem 3.1(1), $\lim _{n \rightarrow \infty}\left\|x_{n}-y\right\|$ exists. Hence $\left\{x_{n}\right\}$ is bounded. Let $\left\{x_{n_{k}}\right\}$ and $\left\{x_{n_{j}}\right\}$ be subsequences of the sequence of $\left\{x_{n}\right\}$ with the two weak limits $q_{1}$ and $q_{2}$, respectively. By Theorem 3.1(2), $\lim _{n \rightarrow \infty}\left\|x_{n_{k}}-S_{i}\left(x_{n_{k}}\right)\right\|=0$ and $\lim _{n \rightarrow \infty}\left\|x_{n_{j}}-S_{i}\left(x_{n_{j}}\right)\right\|=$ 0 for $i=1$,2. By Lemma (2.9), $S_{i}\left(q_{1}\right)=q_{1}$ and $S_{i}\left(q_{2}\right)=q_{2}$ for $i=1,2$. That is, $q_{1}, q_{2} \in F$. Applying Theorem 3.1(1) again, we have $\lim _{n \rightarrow \infty}\left\|x_{n}-q_{1}\right\|$ and $\lim _{n \rightarrow \infty}\left\|x_{n}-q_{2}\right\|$ exist and both $\left\{x_{n_{k}}\right\}$ and $\left\{x_{n_{j}}\right\}$ are sequences converging to $q_{1}$ and $q_{2}$, respectively. By Lemma (2.6), $q_{1}=q_{2}$. Therefore, $\left\{x_{n}\right\}$ converges weakly to a common fixed point in $F$.

Under certain conditions, we can deduce the strong convergence theorem as follows.

Theorem 3.3 Let $\mathcal{H}$ is a uniformly convex Banach space, Suppose that $S_{1}, S_{2}: \mathcal{H} \rightarrow \mathcal{H}$ are two nonexpansive mappings with $F=\operatorname{Fix}\left(S_{1}\right) \cap \operatorname{Fix}\left(S_{2}\right) \neq \emptyset$ and satisfy the Condition $B$. Then the sequence $\left\{x_{n}\right\}$ in (5) converges strongly to a common fixed point of $S_{1}$ and $S_{2}$.

Proof Let $y \in F$. Now by (12), we get

$$
\begin{aligned}
\inf _{y \in F}\left\{\left\|x_{n+1}-y\right\|^{2}\right\} \leq & \inf _{y \in F}\left\{\left\|\omega_{n}-y\right\|^{2}\right\} \\
= & \inf _{y \in F}\left\{\left(1+\gamma_{n}\right)\left\|x_{n}-y\right\|^{2}\right\}+\inf _{y \in F}\left\{-\gamma_{n}\left\|x_{n-1}-y\right\|^{2}\right\} \\
& +\inf _{y \in F}\left\{\gamma_{n}\left(1+\gamma_{n}\right)\left\|x_{n}-x_{n-1}\right\|^{2}\right\} \\
\leq & \inf _{y \in F}\left\{\left\|x_{n}-y\right\|^{2}\right\}+\gamma_{n} \inf _{y \in F}\left\{\left\|x_{n}-y\right\|^{2}\right\}-\gamma_{n} \inf _{y \in F}\left\{\left\|x_{n-1}-y\right\|^{2}\right\} \\
& +\gamma_{n}\left(1+\gamma_{n}\right)\left\|x_{n}-x_{n-1}\right\|^{2} \\
= & \inf _{y \in F}\left\{\left\|x_{n}-y\right\|^{2}\right\}+\gamma_{n}\left[\inf _{y \in F}\left\{\left\|x_{n}-y\right\|^{2}\right\}-\inf _{y \in F}\left\{\left\|x_{n-1}-y\right\|^{2}\right\}\right] \\
& +\gamma_{n}\left(1+\gamma_{n}\right)\left\|x_{n}-x_{n-1}\right\|^{2} .
\end{aligned}
$$


Denote $\Psi_{n}:=\inf _{y \in F}\left\{\left\|x_{n}-y\right\|^{2}\right\}$. Then (26) becomes

$$
\Psi_{n+1} \leq \Psi_{n}+\gamma_{n}\left(\Psi_{n}-\Psi_{n-1}\right)+\delta_{n}
$$

where $\delta_{n}=\gamma_{n}\left(1-\gamma_{n}\right)\left\|x_{n}-x_{n-1}\right\|^{2}$. Observe that by (D1)

$$
\begin{aligned}
\sum_{n=1}^{\infty} \delta_{n} & =\sum_{n=1}^{\infty} \gamma_{n}\left(1+\gamma_{n}\right)\left\|x_{n}-x_{n-1}\right\|^{2} \\
& \leq \sum_{n=1}^{\infty} \gamma_{n}(1+\gamma)(2 K)^{2} \\
& <\infty
\end{aligned}
$$

By Lemma 2.7(2), there exists $\Psi^{*} \in[0, \infty)$ such that $\lim _{n \rightarrow \infty} \Psi_{n}=\Psi^{*}$.

That is, $\lim _{n \rightarrow \infty} \inf _{y \in F}\left\{\left\|x_{n}-y\right\|^{2}\right\}$ exists. Therefore, $\lim _{n \rightarrow \infty} \inf _{y \in F}\left\{\left\|x_{n}-y\right\|\right\}$ exists. Since $S_{1}$ and $S_{2}$ satisfy Condition B, by Theorem 3.1(2) it implies that

$$
\lim _{n \rightarrow \infty} f\left(\inf _{y \in F}\left\{\left\|x_{n}-y\right\|\right\}\right)=0
$$

and, thus,

$$
\lim _{n \rightarrow \infty} \inf _{y \in F}\left\{\left\|x_{n}-y\right\|\right\}=0
$$

So, we can find a subsequence $\left\{x_{n_{j}}\right\}$ of $\left\{x_{n}\right\}$ and a sequence $\left\{x_{j}^{*}\right\} \subset F$ satisfying $\left\|x_{n_{j}}-x_{j}^{*}\right\|<$ $\frac{1}{2^{j}}$. Next we will show that $\left\{x_{j}^{*}\right\}$ is a Cauchy sequence. Let $\epsilon>0$. Since $\lim _{n \rightarrow \infty} \inf _{y \in F}\left\{\| x_{n}-\right.$ $y \|\}=0$, there is $N \in \mathbb{N}$ such that $\inf _{y \in F}\left\{\left\|x_{n}-y\right\|\right\}<\frac{\epsilon}{6}$ for all $n \geq N$. For all $m, n \geq N$, we have

$$
\left\|x_{m}-x_{n}\right\| \leq\left\|x_{m}-y\right\|+\left\|x_{n}-y\right\|
$$

for all $y \in F$. Thus,

$$
\left\|x_{m}-x_{n}\right\| \leq \inf _{y \in F}\left\{\left\|x_{m}-y\right\|+\left\|x_{n}-y\right\|\right\}=\inf _{y \in F}\left\{\left\|x_{m}-y\right\|\right\}+\inf _{y \in F}\left\{\left\|x_{n}-y\right\|\right\}<\frac{\epsilon}{6}+\frac{\epsilon}{6}=\frac{\epsilon}{3}
$$

for all $m, n \geq N$. Also, there is $j_{0} \in \mathbb{N}$ such that $\frac{1}{2^{j} 0}<\frac{\epsilon}{3}$. Choose $M=\max \left\{N, j_{0}\right\}$. Then, for all $j>k \geq M$, we have

$$
\left\|x_{j}^{*}-x_{k}^{*}\right\| \leq\left\|x_{j}^{*}-x_{n_{j}}\right\|+\left\|x_{n_{j}}-x_{n_{k}}\right\|+\left\|x_{n_{k}}-x_{k}^{*}\right\|<\frac{\epsilon}{3}+\frac{\epsilon}{3}+\frac{\epsilon}{3}=\epsilon .
$$

Therefore, $\left\{x_{j}^{*}\right\}$ is a Cauchy sequence and so there exists $q \in \mathcal{H}$ such that $x_{j}^{*}$ converges to $q$. Since $F$ is closed, $q \in F$. As a result, we see that $x_{n_{j}}$ converges to $q$. Since $\lim _{n \rightarrow \infty}\left\|x_{n}-q\right\|$ exists by Theorem 3.1(1), the conclusion follows.

Theorem 3.4 Let $\mathcal{H}$ is a uniformly convex Banach space, Suppose that $S_{1}, S_{2}: \mathcal{H} \rightarrow \mathcal{H}$ are two nonexpansive mappings with $F=\operatorname{Fix}\left(S_{1}\right) \cap \operatorname{Fix}\left(S_{2}\right) \neq \varnothing$ and one of $S_{i}$ is semicompact. Then the sequence $\left\{x_{n}\right\}$ in (5) converges strongly to a common fixed point of $S_{1}$ and $S_{2}$. 
Proof From Theorem 3.1, $\left\{x_{n}\right\}$ is bounded and $\lim _{n \rightarrow \infty}\left\|x_{n}-S_{1}\left(x_{n}\right)\right\|=0=\lim _{n \rightarrow \infty} \| x_{n}-$ $S_{2}\left(x_{n}\right) \|$. By the semicompactness of one of $S_{i}$, there exists $q \in \mathcal{H}$ and a subsequence $\left\{x_{n_{j}}\right\}$ of $\left\{x_{n}\right\}$ such that $x_{n_{j}} \rightarrow q$ as $j \rightarrow \infty$. Then

$$
\begin{aligned}
\left\|q-S_{i}(q)\right\| & \leq\left\|q-x_{n_{j}}\right\|+\left\|x_{n_{j}}-S_{i}\left(x_{n_{j}}\right)\right\|+\left\|S_{i}\left(x_{n_{j}}\right)-S_{i}(q)\right\| \\
& \leq\left\|q-x_{n_{j}}\right\|+\left\|x_{n_{j}}-S_{i}\left(x_{n_{j}}\right)\right\|+\left\|x_{n_{j}}-q\right\| \\
& \rightarrow 0 \quad \text { as } j \rightarrow \infty .
\end{aligned}
$$

Thus, $q \in F$. As in the proof of Theorem 3.3, $\lim _{n \rightarrow \infty} \inf _{y \in F}\left\{\left\|x_{n}-y\right\|\right\}$ exists. We observe that $\inf _{y \in F}\left\{\left\|x_{n_{j}}-y\right\|\right\} \leq\left\|x_{n_{j}}-q\right\| \rightarrow 0$ as $j \rightarrow \infty$, hence $\lim _{n \rightarrow \infty} \inf _{y \in F}\left\{\left\|x_{n}-y\right\|\right\}=0$. It follows, as in the proof of Theorem 3.3, that $\left\{x_{n}\right\}$ converges strongly to a common fixed point of $S_{1}$ and $S_{2}$. This completes the proof.

\section{Numerical illustrations}

We next demonstrate the efficiency of the InerSP iteration and compare it with the MSP iteration defined in [24] by giving some numerical examples. We use program MATLAB R2017a running on Core i7 setup processor installed with 8.00 GB of RAM using Windows 7 . First, we apply our method to solve the following convex feasibility problem (see [31]).

Problem 1 ([31]) For any nonempty closed convex set $C_{i} \subset \mathbb{R}^{N}$ for each $i=0,1, \ldots, m$,

$$
\text { if } C:=\bigcap_{i=1}^{m} C_{i} \neq \emptyset, \quad \text { find } x^{*} \in C \text {. }
$$

Define a mapping $T: \mathbb{R}^{N} \rightarrow \mathbb{R}^{N}$ by

$$
T:=P_{0}\left(\frac{1}{m} \sum_{i=1}^{m} P_{i}\right),
$$

where $P_{i}=P_{C_{i}}, i=0,1,2, \ldots, m$ is the metric projection onto $C_{i}$. Note that $P_{i}$ is nonexpansive for all $i=1,2, \ldots, m$, so this implies that the mapping $T$ is also nonexpansive. Moreover, it is straightforward to check that

$$
\operatorname{Fix}(T)=\operatorname{Fix}\left(P_{0}\right) \cap \bigcap_{i=1}^{m} \operatorname{Fix}\left(P_{i}\right)=C_{0} \cap \bigcap_{i=1}^{m} \operatorname{Fix}\left(P_{i}\right)=C .
$$

We use the inertial S-iteration process (InerSP) and the modified S-iteration process (MSP) to solve Problem 1. For InerSP, set $S_{1}=S_{2}=T, \gamma=0.98, \delta=0.1, \gamma_{n}= \begin{cases}0.95, & n \leq 10^{10}, \\ \frac{1}{(n+1)^{2}}, & n>10^{10},\end{cases}$ and $\beta_{n}=\alpha_{n}=0.65+\frac{1}{(n+1)^{0.25}}$, where $n$ denotes the number of iterations. For MSP, the control parameters are defined the same as InerSP except $\gamma$ and $\gamma_{n}$, which are not parameters in MSP. In the experiment, we set $m=30$ and $C_{i}, i=0,1, \ldots, m$ as a closed ball with center $c_{i} \in \mathbb{R}^{N}$ and radius $r_{i}>0$. Thus, for each $i, P_{i}$ can be computed as

$$
P_{i}(x):= \begin{cases}c_{i}+\frac{r_{i}}{\left\|c_{i}-x\right\|}\left(x-c_{i}\right) & \text { if }\left\|c_{i}-x\right\|>r_{i} \\ x & \text { if }\left\|c_{i}-x\right\| \leq r_{i} .\end{cases}
$$


Table 1 Convergence comparison of MSP and InerSP for the given function in Problem 1

\begin{tabular}{rcl}
\hline \multicolumn{1}{l}{$n$} & MSP iteration Error $\left\|z_{n}\right\|_{\infty}$ & InerSP iteration Error $\left\|x_{n}\right\|_{\infty}$ \\
\hline 0 & 1 & 1 \\
1 & 0.146860263 & 0.146905257 \\
2 & 0.144519281 & 0.169202619 \\
3 & 0.142508272 & 0.224124309 \\
4 & 0.140748768 & 0.240030476 \\
$\vdots$ & $\vdots$ & $\vdots$ \\
271 & 0.058053817 & 0.010021818 \\
272 & 0.057968808 & 0.010009268 \\
273 & 0.057884185 & 0.009996786 \\
$\vdots$ & $\vdots$ & \\
12,664 & $\vdots$ & \\
12,665 & 0.010000328 & \\
CPU times (sec) & 0.009999947 & \\
\hline
\end{tabular}

Choose $r_{i}:=1$ for all $i=0,1, \ldots, m, c_{0}:=0, c_{1}=[1,0, \ldots, 0]$, and $c_{2}=[-1,0, \ldots, 0]$. For $3 \leq$ $i \leq m, c_{i} \in(-1 / \sqrt{N}, 1 / \sqrt{N})$ are randomly chosen. From the choice of $c_{1}, c_{2}$ and $r_{1}, r_{2}$, we have $\operatorname{Fix}(T)=\{0\}$. We select initial points $x_{0}=\operatorname{rand}(N, 10)$ and $x_{1}=x_{0}+\frac{\operatorname{rand}(N, 1)}{10,000}$ where $N=30$. Since $\operatorname{Fix}(T)=\{0\}$, we can consider the error as

$$
\left\|x_{n}\right\|_{\infty}=\max \left\{\left|x_{n}(1)\right|,\left|x_{n}(2)\right|, \ldots,\left|x_{n}(N)\right|\right\}<\epsilon=0.01,
$$

and take it to be the stopping criterion. In Table $1, n$ denotes the number of iterations, $\left\{x_{n}\right\}$ and $\left\{z_{n}\right\}$ denote the sequence of approximated fixed points generated by InerSP and MSP, respectively. The results are shown in Table 1 .

The results are listed in Table 1, which illustrate that the errors for both the MSP iteration and the InerSP iteration reduce, which means that the approximated solutions for both methods converge to the fixed point 0 . In addition, from Table 1 and Fig. 1 , we can see that $\left\|x_{n}\right\|_{\infty} \leq\left\|z_{n}\right\|_{\infty}$ and $\lim _{n \rightarrow \infty} \frac{\left\|x_{n}\right\|_{\infty}}{\left\|z_{n}\right\|_{\infty}}=0$ so the InerSP iteration behaves better than the MSP and the sequence $\left\{x_{n}\right\}$ converges faster than $\left\{z_{n}\right\}$. Moreover, the running CPU time for finding the fixed point using InerSP is much less than MSP.

In the next example, we perform a numerical experiment to find a common fixed point of two nonexpansive mappings.

Problem 2 Define $S_{1}, S_{2}: \mathbb{R}^{2} \rightarrow \mathbb{R}^{2}$ by

$$
S_{1}(x, y)=\left(\frac{1+x}{2}, 1+\frac{y}{2}\right)
$$

and

$$
S_{2}(x, y)=\left(x, 3-\frac{y}{2}\right)
$$

It is easy to check that both $S_{1}$ and $S_{2}$ are nonexpansive on $\mathbb{R}^{2}$. In this problem, for InerSP we set $\gamma=0.98, \delta=0.1, \gamma_{n}=\left\{\begin{array}{ll}0.25, & n \leq 10^{10} \\ \frac{1}{(n+1)^{2}}, & n>10^{10}\end{array}\right.$, and $\beta_{n}=\alpha_{n}=0.65+\frac{1}{(n+1)^{0.25}}$. For MSP we set $\gamma_{n}=0, \beta_{n}=\alpha_{n}=0.65+\frac{1}{(n+1)^{0.25}}$. We note that $x^{*}=(1,2)$ is the commom fixed point of $S_{1}$ 


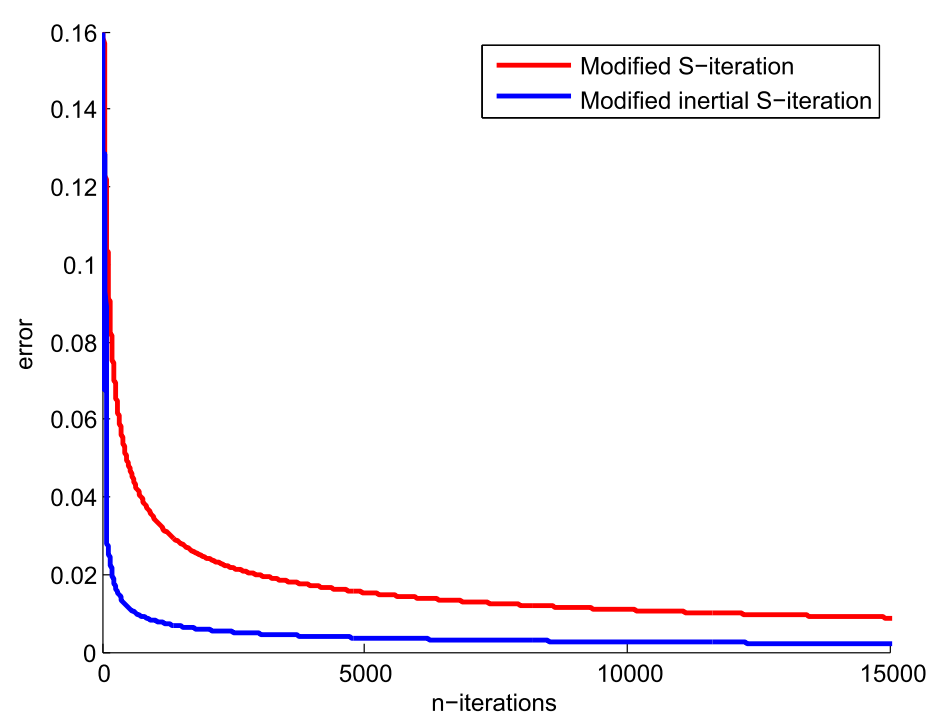

Figure 1 Error comparison between MSP and InerSP

Table 2 Convergence comparison of MSP and InerSP for the given function in Problem 2

\begin{tabular}{|c|c|c|c|c|c|c|}
\hline \multirow{2}{*}{$\begin{array}{l}\text { Iteration } \\
n\end{array}$} & \multicolumn{2}{|c|}{$\operatorname{MSP} z_{n}=\left(z_{1 n}, z_{2 n}\right)$} & \multicolumn{2}{|c|}{$\operatorname{InerSP} x_{n}=\left(x_{1 n}, x_{2 n}\right)$} & \multicolumn{2}{|c|}{ Error $\left\|x_{n}-x_{0}\right\|_{2}$} \\
\hline & $z_{1 n}$ & $z_{2 n}$ & $x_{1 n}$ & $x_{2 n}$ & MSP & InerSP \\
\hline 1 & 721 & -5 & 721 & -5 & 720.0340 & 720.0340 \\
\hline 2 & 393.4 & 3.3825 & 423.5113 & 53.0044 & 392.4024 & 425.5787 \\
\hline 3 & 232.8733 & 1.8392 & 206.7190 & -5.6175 & 231.8733 & 205.8600 \\
\hline 4 & 140.6855 & 2.0138 & 92.2796 & 3.9063 & 139.6856 & 91.2944 \\
\hline & & $\vdots$ & $\vdots$ & : & $\vdots$ & $\vdots$ \\
\hline 13 & 2.6602 & 2 & 1.0007 & 2 & 1.0177 & 0.0007 \\
\hline 14 & 2.0177 & 2 & & & 0.6239 & \\
\hline : & $\vdots$ & $\vdots$ & & & $\vdots$ & \\
\hline 29 & 1.0007 & 2 & & & 0.0007 & \\
\hline CPU times (sec) & 0.010388 & & 0.001049 & & & \\
\hline
\end{tabular}

and $S_{2}$. Set $x_{0}=(500,1000)$ and $x_{1}=(721,-5)$ as the initial values. Let $\left\{z_{n}\right\}$ and $\left\{x_{n}\right\}$ be sequences generated by MSP and InerSP, respectively, where $z_{n}=\left(z_{1 n}, z_{2 n}\right)$ and $x_{n}=\left(x_{1 n}, x_{2 n}\right)$ are in $\mathbb{R}^{2}$. Moreover, we take err $=\left\|x_{n}-x^{*}\right\|_{2}$ to be the error of the iterative algorithm where $\|\cdot\|_{2}$ is the Euclidean norm. The results are shown in Table 2.

From Table 2, we see that both $\left\{z_{n}\right\}$ and $\left\{x_{n}\right\}$ converge to fixed point $x^{*}=(1,2)$. If we iterate until the error is less than 0.001 the MSP converges to fixed point in 29 iterations and InerSP converges in 13 iterations. From Table 2 and Fig. 2, it can be observed that $\left\|x_{n}-x^{*}\right\| \leq\left\|z_{n}-x^{*}\right\|$ for all $n \geq 2$ and $\lim _{n \rightarrow \infty} \frac{\left\|x_{n}-x^{*}\right\|_{2}}{\left\|z_{n}-x^{*}\right\|_{2}}=0$ so the sequence $\left\{x_{n}\right\}$ converges faster than $\left\{z_{n}\right\}$. In addition, the running time to find the common fixed point using InerSP is 10 times less than MSP. As illustrated in the two examples, we can perceive that the InerSP iteration has a better behavior than the MSP iteration.

\section{Conclusions}

In this work, we introduce a new iteration method, namely InerSP, by combining a modified S-iteration (MSP) with the inertial extrapolation. We also analyze the behavior of our 


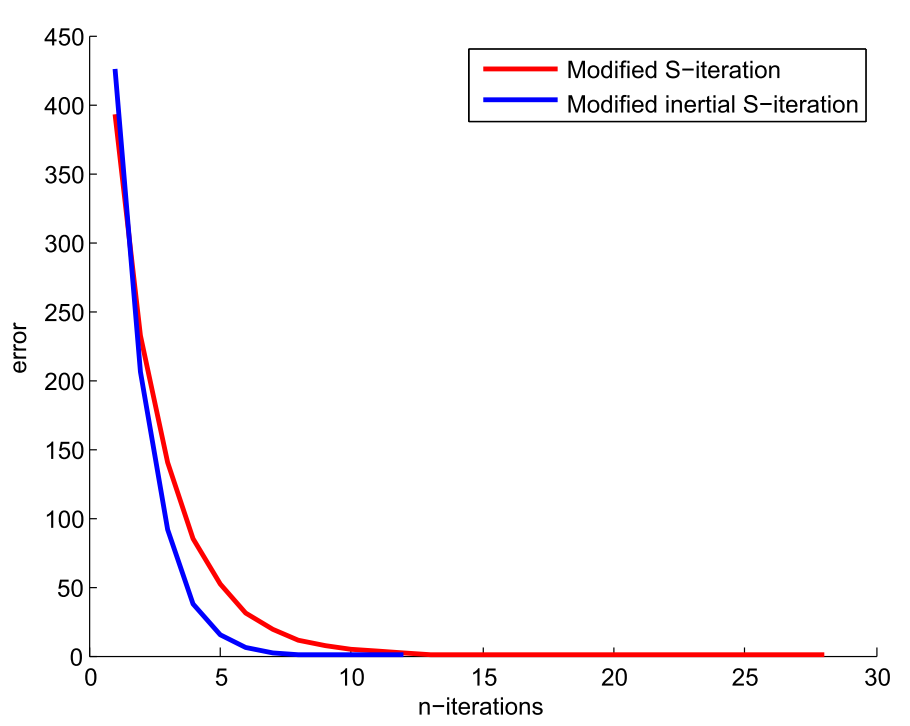

Figure 2 Error comparison between MSP and InerSP

InerSP method. Although the number of steps of the iteration process of the InerSP is higher than MSP, the numerical examples show that sequences generated by InerSP iteration converge to fixed points more rapidly than MSP iteration when using the number of iterations and CPU running times as measures.

\section{Acknowledgements}

The authors would like to thank the referee for helpful and detailed comments.

Funding

This article is funded by the authors.

\section{Abbreviations}

InerSP, Inertial S-iteration process; MSP, A modified S-iteration; CPU, Central Processing Unit.

\section{Availability of data and materials}

Not applicable.

\section{Competing interests}

The authors declare that they have no competing interests.

Authors' contributions

All authors read and approved the final manuscript.

\section{Publisher's Note}

Springer Nature remains neutral with regard to jurisdictional claims in published maps and institutional affiliations.

Received: 20 September 2018 Accepted: 16 January 2019 Published online: 18 February 2019

\section{References}

1. Ishikawa, S.: Fixed points by a new iteration method. Proc. Am. Math. Soc. 44, 147-150 (1974)

2. Chen, P., Huang, J., Zhang, X.: A primal-dual fixed point algorithm for convex separable minimization with applications to image restoration. Inverse Probl. 29, 025011 (2013)

3. liduka, H.: Iterative algorithm for triple-hierarchical constrained nonconvex optimization problem and its application to network bandwidth allocation. SIAM J. Optim. 22, 862-878 (2012)

4. Micchelli, C.A., Shen, L., Xu, Y.: Proximity algorithms for image models: denoising. Inverse Probl. 27(4), 045009 (2011)

5. Zhou, H., Zhou, Y., Feng, G.: Iterative methods for solving a class of monotone variational inequality problems with applications. J. Inequal. Appl. 2015, 68 (2015)

6. Noor, M.A.: New approximation schemes for general variational inequalities. J. Math. Anal. Appl. 251, 217-229 (2000)

7. Chambolle, A.: An algorithm for total variation minimization and applications. J. Math. Imaging Vis. 20, 89-97 (2004)

8. Mann, W.R.: Mean value methods in iteration. Proc. Am. Math. Soc. 4, 506-510 (1953) 
9. Phuengrattana, W., Suantai, S.: On the rate of convergence of Mann, Ishikawa, Noor and SP-iterations for continuous functions on an abitrary interval. J. Comput. Appl. Math. 235, 3006-3014 (2011)

10. Phuengrattana, W., Suantai, S.: Comparison of the rate of convergence of various iterative methods for the class of weak contrations in Banach spaces. Thai J. Math. 11, 217-226 (2013)

11. Yuan, H.: A splitting algorithm in a uniformly convex and 2-uniformly smooth Banach space. J. Nonlinear Funct. Anal. 2018, Article ID 26 (2018)

12. Zhao, J., Zong, H., Muangchoo, K., Kumam, P., Cho, Y.J.: Algorithms for split common fixed point in Hilbert spaces. J. Nonlinear Var. Anal. 2, 273-286 (2018)

13. Mainge, P.E.: Convergence theorems for inertial KM-type algorithm. J. Comput. Appl. Math. 219, 223-236 (2008)

14. Dong, Q.L., Yuan, H.B., Cho, Y.J., Rassias, T.M.: Modified inertial Mann algorithm and inertial CQ-algorithm for nonexpansive mappings. Optim. Lett. 12(1), 87-102 (2018). https://doi.org/10.1007/s11590-016-1102-9

15. Alvarez, F., Attouch, H.: An inertial proximal method for maximal monotone operators via discretization of a nonlinear oscillator with damping. Set-Valued Anal. 9(1-2), 3-11 (2001)

16. Moudafi, A., Oliny, M.: Convergence of a splitting inertial proximal method for monotone operators. J. Comput. Appl. Math. 155, 447-454 (2003)

17. Lorenz, D.A., Pock, T.: An inertial forward-backward algorithm for monotone inclusions. J. Math. Imaging Vis. 51 311-325 (2015)

18. Chan, R.H., Ma, S., Yang, J.F.: Inertial proximal ADMM for linearly constrained separable convex optimization. SIAM J. Imaging Sci. 8(4), 2239-2267 (2015)

19. Beck, A., Teboulle, M.: A fast iterative shrinkage-thresholding algorithm for linear inverse problems. SIAM J. Imaging Sci. 2(1), 183-202 (2009)

20. Chambolle, A., Dossal, C: On the convergence of the iterates of the "fast iterative shrinkage/ thresholding algorithm". J. Optim. Theory Appl. 166, 968-982 (2015)

21. Bot, R.I., Csetnek, E.R., Hendrich, C.: Inertial Douglas-Rachford splitting for monotone inclusion problems. Appl. Math. Comput. 256, 472-487 (2015)

22. Alvarez, F.: Weak convergence of a relaxed and inertial hybrid projection-proximal point algorithm for maximal monotone operators in Hilbert space. SIAM J. Optim. 14(3), 773-782 (2004)

23. Polyak, B.T.: Some methods of speeding up the convergence of iteration methods. USSR Comput. Math. Math. Phys. 4(5), 1-17 (1964)

24. Suparatulatorn, R., Cholamjiak, W., Suantai, S.: A modified S-iteration process for G-nonexpansive mappings in Banach spaces with graphs. Numer. Algorithms 77(2), 479-490 (2018). https://doi.org/10.1007/s11075-017-0324-y

25. Shahzad, S., Al-Dubiban, R.: Approximating common fixed points of nonexpansive mappings in Banach spaces. Georgian Math. J. 13(3), 529-537 (2006)

26. Nakajo, K., Takahashi, W.: Strong convergence theorems for nonexpansive mappings and nonexpansive semigroups. J. Math. Anal. Appl. 279, 372-379 (2003)

27. Berinde, V:: Iterative Approximation of Fixed Points. Editura Dfemeride, Baia Mare (2002)

28. Dong, Q.L., Lu, Y.Y.: A new hybrid algorithm for a nonexpansive mapping. Fixed Point Theory Appl. 2015, 37 (2015)

29. Alvarez, F: Weak convergence of a relaxed and inertial hybrid projection-proximal point algorithm for maximal monotone operators in Hilbert space. SIAM J. Optim. 14(3), 773-782 (2004)

30. Bauschke, H.H., Combettes, P.L.: Convex Analysis and Monotone Operator Theory in Hilbert Spaces. Springer, Berlin (2011)

31. Sakurai, K., Linduka, H.: Acceleration of the Halpern algorithm to search for a fixed point of a nonexpansive mapping. Fixed Point Theory Appl. 2014, 202 (2014)

\section{Submit your manuscript to a SpringerOpen ${ }^{\circ}$ journal and benefit from:}

- Convenient online submission

- Rigorous peer review

- Open access: articles freely available online

- High visibility within the field

- Retaining the copyright to your article

Submit your next manuscript at $\gg$ springeropen.com 